\title{
Aspectos ecológicos da população de Cosmopolites sordidus, (Germar) (Coleoptera: Curculionidae) em São Miguel do Iguaçu, PR
}

\section{Ecological aspects of a Cosmopolites sordidus (Germar) (Coleoptera: Curculionidae) population in São Miguel do Iguaçu, PR.}

\author{
Tânia Mari Vicentini Prestes ${ }^{1 *}$; Agostinho Zanini ${ }^{1}$; Luis Francisco Angeli Alves ${ }^{2}$; \\ Antonio Batista Filho ${ }^{3}$, Cristiane Rohde ${ }^{4}$
}

\section{Resumo}

Estudou-se a dinâmica populacional de Cosmopolites sordidus (Germar) em cultivo de banana (cultivar Nanicão), em São Miguel do Iguaçu, PR, através de iscas do tipo telha, entre junho/2003 a maio/2004. Atribuiu-se conceito ao estado de conservação da isca, visando observar sua durabilidade e atratividade. Registraram-se adultos infectados por fungos entomopatogênicos, sendo também encontrados predadores nas iscas. Realizou-se um bioensaio com isolados de Beauveria bassiana da área experimental e de Centros de Pesquisa do Brasil, para avaliar a patogenicidade em C. sordidus. Verificou-se que os picos populacionais de adultos de $C$. sordidus ocorreram em junho e julho, período de temperaturas amenas e baixas precipitações, enquanto que as larvas foram mais abundantes em dezembro. Os insetos predadores encontrados na área pertenciam às ordens: Coleoptera (Carabidae), Dermaptera (Forficulidae), Hemiptera (Reduviidae), Hymenoptera (Formicidae) e aranhas das famílias Ctenidae, Clubionidae e Lycosidae, com pico populacional dois meses após o pico da população da praga. O número de adultos de $C$. sordidus infectados por B. bassiana foi baixo, com média anual de 0,44\%. Em laboratório, os isolados de $B$. bassiana mostraram-se patogênicos aos insetos.

Palavras-chave: Insecta, flutuação populacional, manejo integrado

\begin{abstract}
The population dynamics of Cosmopolites sordidus (Germar) was studied in banana crops (cultivar Nanicão) at São Miguel do Iguaçu, PR, using roof-tile-like baits, between June/2003 and May/2004. Adults infected by entomopathogenic fungi were recorded, and predators were also found on the baits. A comparative bioassay was carried out between the Beauveria bassiana isolate obtained from the experiment area and from other regions in Brazil against $C$. sordidus adults. The population peaks of $C$. sordidus adults occurred in June and July, a period with mild temperatures and low precipitation. The population of $C$. sordidus larvae, however, was concentrated in December. The insect predators found in the area were insects of the following orders: Coleoptera (Carabidae), Dermaptera (Forficulidae), Hemiptera (Reduviidae), Hymenoptera (Formicidae), and spiders of the families Ctenidae, Clubionidae, and Lycosidae, with a population peak two months after the pest population peak. A low number of $C$. sordidus adults infected by $B$. bassiana was found, with an annual mean of $0.44 \%$. In the laboratory, the $B$. bassiana isolates were pathogenic to the insects.
\end{abstract}

Key words: Insecta. Population fluctuation. Integrated management.

1 Professores do Centro Federal de Educação Tecnológica do Paraná. Medianeira, PR. E-mail: taniaprestes@innet.com.br.

2 Universidade Estadual do Oeste do Paraná/CCBS, Laboratório de Zoologia. Cascavel. E-mail: lfaalves@ unioeste.br. Bolsista de Produtividade em Pesquisa, CNPq.

3 Instituto Biológico, São Paulo. E-mail: batistaf@biologico.sp.gov.br.

4 Programa de Mestrado em Entomologia, Universidade Federal de Lavras, Departamento de Entomologia

* Autor para correspondência

Recebido para publicação 27/09/05 Aprovado em 05/06/06 


\section{Introdução}

No Brasil, a banana é cultivada em todos os Estados, desde a faixa litorânea até os planaltos interioranos, já que se constitui em meio de subsistência para as populações rurais, além de ser um produto de exportação. Embora o Brasil seja um dos maiores produtores mundiais de banana, exporta somente uma pequena parcela de sua produção, muito inferior, por exemplo a de outros países como o Equador, cuja produção é menor que a brasileira, mas que exporta praticamente $65 \%$ de sua produção. Esta baixa representatividade do Brasil, deve-se principalmente à baixa produtividade e ao alto índice de perdas, causadas principalmente por problemas fitossanitários (BATISTA FILHO; TAKADA; CARVALHO, 2002).

Dentre os problemas fitossanitários ressalta-se o Cosmopolites sordidus (Germar) (Coleoptera: Curculionidae) que é praga em quase todos os países produtores de banana, provocando perdas de 30 a 90\% (GOLD; PINESE; PEÑA, 2002). No Brasil, principalmente no estado de São Paulo, foi considerada a praga mais importante na década de 80 (SUPLICY; SAMPAIO, 1982). Segundo Gallo et al. (2002), infestações de 12 larvas/planta podem afetar a produção entre 20 a 50\%. Os danos causados à bananeira ocorrem, principalmente, quando a praga se encontra na fase larval, quando produz galerias nos rizomas e na parte inferior do pseudocaule, afetando o desenvolvimento e a produção, além de causar a queda das plantas pela ação dos ventos (BATISTA FILHO; TAKADA; CARVALHO, 2002).

O adulto tem hábitos noturnos e é bastante ativo para ovopositar, alimentar e acasalar, sendo pouco ativo no inverno, pois é sensível a baixas temperaturas (SUPLICY; SAMPAIO, 1982; SILVA, 1985; VIANA, 1992).

Estudos de estimativa populacional e de controle desta praga são realizados por meio de iscas, confeccionadas com o pseudocaule da bananeira, recomendando-se de 20 a 50 iscas/ha (FANCELLI, 1999; FAZOLIN; LEDO; AZEVEDO, 2000;
BATISTA FILHO; TAKADA; CARVALHO, 2002).

Considerando-se o fato deste estudo ser inédito no Paraná, bem como o valor econômico e prejuízos causados na bananicultura por esta praga, foram estudados a dinâmica populacional da praga e dos seus inimigos naturais e a patogenicidade de isolados do fungo B. bassiana para o inseto.

\section{Material e Métodos}

\section{Monitoramento de Cosmopolites sordidus}

Os dados foram coletados em uma área de 9,0 ha, cultivada por plantas de bananeiras da variedade nanicão com aproximadamente 9 anos de idade, não tratada com inseticidas, e localizada no município de

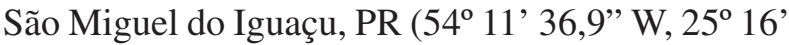
24,1 " S, a $364 \mathrm{~m}$ de altitude).

$\mathrm{O}$ experimento foi instalado em 3 ha mantendose bordaduras de $6 \mathrm{~m}$ no contorno da área e de $3 \mathrm{~m}$ entre os talhões, sendo empregada a metodologia desenvolvida por Batista Filho et al. (1991) para avaliação da dinâmica populacional da praga. A avaliação populacional de $C$. sordidus foi realizada, entre junho de 2003 a maio de 2004, com a utilização de 80 iscas do tipo telha, confeccionadas com um pedaço de pseudocaule de aproximadamente $40 \mathrm{~cm}$ de comprimento, seccionado longitudinalmente ao meio. As iscas foram colocadas ao lado das bananeiras, com a parte seccionada voltada para o solo, previamente limpo.

As avaliações foram realizadas a cada 15 dias, e as armadilhas eram classificadas quanto ao seu estado de conservação, a fim de observar sua durabilidade e atratividade. A classificação foi baseada em conceitos atribuídos de acordo com o seu estado de preservação, podendo ser, bom para àquelas menos escurecidas, mais endurecidas e com menor teor de água; regular para iscas mais preservadas quanto à forma, mas com avançado estado de decomposição, com liberação de odores e contenção de bastante umidade; e ruim para as iscas 
endurecidas, secas e deformadas em relação ao seu aspecto original.

Em seguida, os insetos (larvas, pupas e adultos) encontrados foram registrados e liberados no local, sendo as iscas substituídas, após cada avaliação.

Os locais em que as iscas foram dispostas, foram caracterizados quanto à luminosidade/sombreamento e existência ou não de plantas invasoras.

Durante as avaliações observou-se a presença de adultos da broca infectados por fungos entomopatogênicos e também predadores, que quando encontrados foram coletados e identificados ao nível de ordem e família pelo Prof. Dr. Gabriel Simões de Andrade, (UNIOESTE, Cascavel, PR). No caso de fungos, os insetos foram coletados, e o patógeno isolado, identificado e armazenado na Coleção de Entomopatógenos do Laboratório de Zoologia da UNIOESTE, Campus de Cascavel.

Os dados climáticos foram fornecidos pela Estação Meteorológica do CEFET (Centro Federal de Educação Tecnológica do Paraná), localizada nas proximidades da área experimental, em Medianeira, PR.
A dinâmica populacional foi analisada com base em análise gráfica e correlação linear simples entre o número de insetos encontrados nas iscas e os fatores climáticos (precipitação pluviométrica, temperatura e umidade relativa), bem como com o aspecto da isca. Realizou-se também a análise estatística confrontando-se número de insetos registrados nas iscas e sua localização no bananal pelo método teste $\mathrm{X}^{2}$ de dependência, utilizando-se o programa Microsoft Excel $®$.

A avaliação da patogenicidade de isolados de Beauveria bassiana (Bals.) Vuill. para adultos de C. sordidus

O estudo foi realizado no Laboratório de Zoologia da UNIOESTE, Campus de Cascavel, PR. Foram avaliados quatro isolados de fungos pertencentes à espécie de B. bassiana provenientes das coleções do Instituto Biológico de São Paulo, Universidade Estadual de Londrina (UEL) e da UNIOESTE, PR (Tabela 1).

Tabela 1. Isolados do fungo Beauveria bassiana utilizados nos testes de eficiência para controle em laboratório

\begin{tabular}{lll}
\hline \multicolumn{1}{c}{ Código dos Fungos } & \multicolumn{1}{c}{ Espécie de fungo } & \multicolumn{1}{c}{ Origem do fungo } \\
\hline UNIOESTE 39 & B. bassiana & adultos de $C$. sordidus, bananal São Miguel do Iguaçu, PR. \\
UEL 50 & B. bassiana & adultos de Hypothenemus hampei, Londrina, PR. \\
CB66 & B. bassiana & adultos de H. hampei, São José do Rio Pardo, SP. \\
UEL 25 & B. bassiana & origem desconhecida \\
\hline
\end{tabular}

Previamente à realização dos bioensaios, os fungos foram multiplicados em meio de cultura batatadextrose-ágar (BDA) em placas de Petri, incubados em câmara B.O.D. $\left(26 \pm 1^{\circ} \mathrm{C}, 14\right.$ horas de fotofase), durante dez dias até a plena conidiogênese. Após isso, os conídios foram raspados da superfície do meio e, em seguida, armazenados em tubos de vidro, em freezer $\mathrm{a}-10^{\circ} \mathrm{C}$, até a realização dos bioensaios, por um período de no máximo 30 dias.

O procedimento experimental foi baseado no estudo de Jordão et al. (1999), e constou do preparo de suspensões de conídios em água destilada mais espalhante adesivo Tween $80(0,01 \%)$, quantificadas em câmara de Neubauer e padronizadas na concentração de $2 \times 10^{8}$ conídios $/ \mathrm{mL}$, com no mínimo $90 \%$ de viabilidade.

Os adultos de $C$. sordidus, previamente coletados na área experimental, foram mantidos em laboratório, para observação do estado de sanidade, posteriormente, transferidos para placas de Petri de plástico, onde foram imersos em $1 \mathrm{~mL}$ de suspensão de fungo e agitados manualmente durante um minuto. 
Os insetos do tratamento controle foram imersos em uma solução de espalhante adesivo. Para cada isolado foram preparadas quatro repetições com 10 indivíduos.

Após a inoculação, os insetos foram transferidos para placas de Petri, contendo papel-filtro e pseudocaule de bananeira da cv. nanicão em seu interior, mantidos em uma câmara B.O.D. $\left(26 \pm 1^{\circ} \mathrm{C}\right.$, fotofase de 14 horas) e avaliados diariamente, durante 20 dias, trocando-se o alimento a cada dois dias.

Os insetos mortos foram imersos em solução de álcool $70 \%$ e em água destilada, sendo individualizados, e mantidos em câmara úmida nas mesmas condições descritas, a fim de permitir o desenvolvimento dos fungos, confirmando o agente causal da mortalidade.

Os dados obtidos foram transformados pelo arcsen " $x$ e analisados estatisticamente quanto à variância, utilizando-se o teste $\mathrm{F}$, sendo as médias de mortalidade comparadas entre si por meio do teste de Tukey, ambos com 5\% de significância, utilizandose o programa estatístico Sisvar.

\section{Resultados e Discussão}

O número médio de $C$. sordidus nas iscas, oscilou entre 2,9 a 6,1 , sendo os picos populacionais de adultos verificados nos meses de junho e julho de 2003 e as épocas de menor incidência em janeiro e maio de 2004 (Figura 1). No entanto, picos no mês de outubro foram observado por Arleu (1982) no Espírito Santo, em bananal cv. Prata. No Vale do Ribeira, estado de São Paulo, em bananal com cv. Nanicão e Nanica, Batista Filho et al. (1991), registraram pico populacional no mês de março, com 9,3 adultos/isca e em maio com 6,45 adultos/isca, respectivamente. Além disso, na Venezuela, Martínez e Godoy (1988) verificaram pico de adultos em maio e julho, com queda da população em outubro e dezembro.

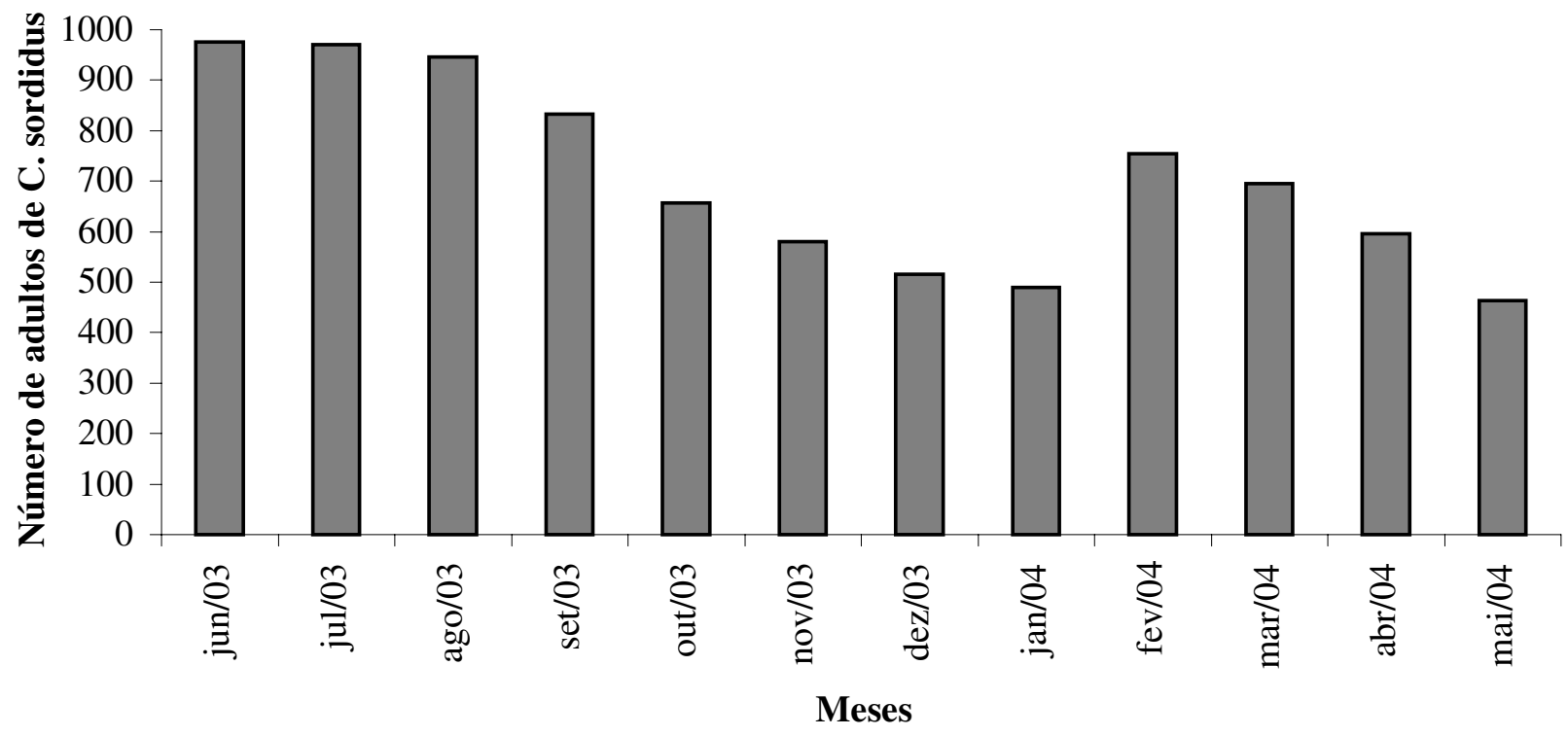

$\square$ Número de C. sordidus

Figura 1. Flutuação populacional de Cosmopolites sordidus em bananal do cv. Nanicão. São Miguel do Iguaçu, PR, junho de 2003 a maio de 2004. 
Provavelmente, as variações dos picos populacionais obtidos neste estudo e pelos diferentes autores ocorreram em função dos fatores bióticos e abióticos específicos de cada local, haja vista que os autores citados realizaram seus estudos em áreas litorâneas e exploradas com diferentes cultivares de bananeiras.
A análise da correlação entre as médias das temperaturas máxima e mínima do período e a população do moleque-da-bananeira não foi significativa, indicando que, as mesmas exerceram pouca influência na flutuação populacional dos adultos de $C$. sordidus (Tabela 2). Em relação a este fator ambiental e a população do inseto, Arleu (1982), Silva (1985) e Batista Filho et al. (1991), também obtiveram correlação não significativa.

Tabela 2. Equações de regressão e coeficientes de correlação encontrados entre fatores climáticos, e o número mensal de larvas e adultos de Cosmopolites sordidus por isca em bananal do cv. Nanicão. São Miguel do Iguaçu, PR, junho de 2003 a maio de 2004.

\begin{tabular}{clc}
\hline Fatores ambientais & Equações de regressão & Coeficientes de correlação $(\mathrm{r})$ \\
\hline Adultos de C. sordidus & & $-0,59713^{*}$ \\
Precipitação pluvial $(\mathrm{mm})$ & $\mathrm{y}=-1,1845 \mathrm{x}+880,46$ & $-0,31981^{* *}$ \\
Temperatura máxima $\left({ }^{\circ} \mathrm{C}\right)$ & $\mathrm{y}=-15,676 \mathrm{x}+1137$ & $-0,52945^{* *}$ \\
Temperatura Mínima $\left({ }^{\circ} \mathrm{C}\right)$ & $\mathrm{y}=-29,674 \mathrm{x}+1214,6$ & $-0,06723^{\mathrm{ns}}$ \\
Umidade relativa do ar $(\%)$ & $\mathrm{y}=-1,3576 \mathrm{x}+789,65$ & \\
& & $0,419785^{* *}$ \\
Larvas de C. sordidus & & $0,257681^{\mathrm{ns}}$ \\
Precipitação pluvial $(\mathrm{mm})$ & $\mathrm{y}=0,1469 \mathrm{x}+10,548$ & $0,453686^{* *}$ \\
Temperatura máxima $\left({ }^{\circ} \mathrm{C}\right)$ & $\mathrm{y}=2,2286 \mathrm{x}-29,081$ & $0,344436^{* *}$ \\
Temperatura Mínima $\left({ }^{\circ} \mathrm{C}\right)$ & $\mathrm{y}=4,4864 \mathrm{x}-44,701$ & \\
Umidade relativa do ar $(\%)$ & $\mathrm{y}=1,2273 \mathrm{x}-43,3$ & \\
\hline
\end{tabular}

$* 0,6 \leq(\mathrm{r}) \leq 1$ variáveis de correlação significativa; ${ }^{* *} 0,3 \leq(\mathrm{r}) \leq 0,6$ correlação relativamente fraca entre as variáveis e ${ }^{\text {ns }}$ $0<(\mathrm{r})<0,3$ correlação muito fraca entre as variáveis (CRESPO, 1997).

Entretanto, em relação à precipitação pluviométrica, observou-se que a interação foi significativa $(r=-0,5971)$ quanto à presença dos adultos na isca, visto que, nos períodos de maior precipitação (outubro a dezembro) a média de adultos por isca foi mais baixa (Figura 2) (Tabela 2). Provavelmente, esse fato ocorreu devido ao acúmulo excessivo de água na isca, tornando-a inviável à sobrevivência do inseto.
Resultados semelhantes foram obtidos por Arleu et al. (1985), que registraram picos populacionais do inseto adulto em bananal do cv. prata, no Espírito Santo, nos meses de menor precipitação pluviométrica, obtendo uma correlação significativa entre os insetos adultos e a precipitação. 


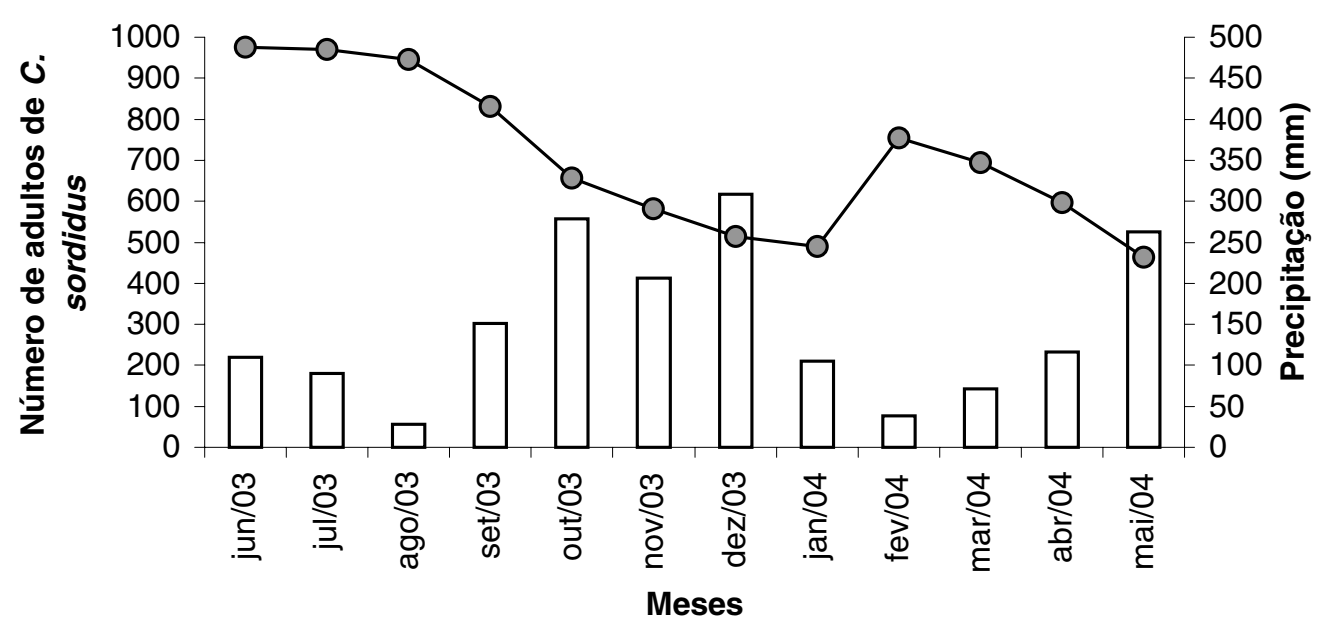

$\square$ Precipitação $(\mathrm{mm})$

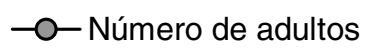

Figura 2. Flutuação de adultos de Cosmopolites sordidus e precipitação em bananal do cv. Nanicão. São Miguel do Iguaçu, PR, junho de 2003 a maio de 2004.

Também Batista Filho et al. (1991), em São Paulo, assinalaram queda brusca da população de adultos (1,15 adultos/isca) em janeiro, quando ocorreu o maior índice de precipitação (336,8 mm) e, na Venezuela, Martínez e Godoy (1988) obtiveram menor captura de adultos nos períodos de maior precipitação.

Considerando que a superfície do solo é o habitat deste inseto, os índices de precipitação são necessários para a manutenção da umidade do mesmo, de forma a torná-lo ou mantê-lo adequado ao inseto, já que, em condições de laboratório esses insetos morrem em cerca de 72 horas quando mantidos sobre substratos secos (GOLD et al., 1998).

Assim, possivelmente as variações da umidade relativa do ar no período do estudo tiveram pouca influência sobre a dinâmica populacional dos adultos, sendo mais relevante à umidade do solo, mantida pela cobertura morta da própria cultura, que possibilitou um ambiente mais úmido e propício para a sobrevivência mesmo nos períodos de baixa umidade relativa do ar. Este fator foi investigado por Oliveira e Souza (2003) e Mcintyre et al. (2003), que constataram o efeito benéfico da cobertura morta dos resíduos da bananeira sobre a manutenção do teor de umidade do solo, tornando-o mais elevado em relação ao tratamento sem cobertura, devido à maior retenção da água de superfície, que se infiltra, acumulando-se nas camadas inferiores.

Em relação às larvas de $C$. sordidus, seu pico populacional ocorreu no mês de dezembro, correspondendo ao mês com as médias de temperatura mais elevadas $\left(29,7^{\circ} \mathrm{C}\right)$ e de maior precipitação pluviométrica (308,6 mm) (Figura 3).

Resultados semelhantes foram obtidos por Batista Filho et al. (1991), que verificaram o pico de larvas para o cv. nanicão em janeiro, mês de maior precipitação pluviométrica e com temperaturas bastante elevadas, e não registraram a presença de larvas nas iscas nos meses de julho e agosto, justamente quando as médias de temperatura mínima foram as mais baixas.

Quanto à condição de preservação das iscas observou-se, em maior número, a isca em estado regular (77\% em relação às demais iscas) (Tabela 3). Esta isca, preservada quanto à sua forma, mas com avançado estado de decomposição, apresentouse mais úmida em relação às iscas de estado de conservação boa e ruim e com maior liberação de odores (Figura 4). 


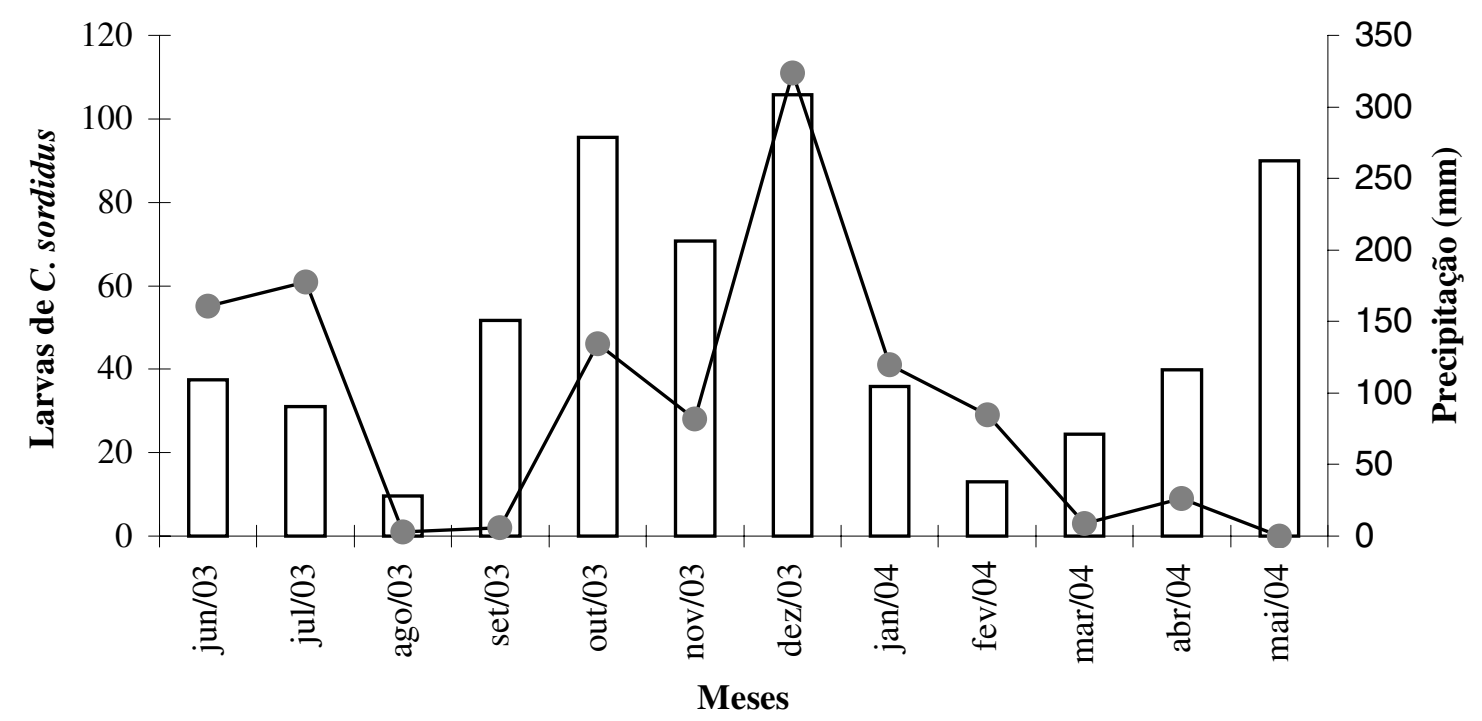

$\square$ Precipitação

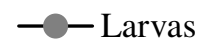

Figura 3. Flutuação populacional de larvas de Cosmopolites sordidus, em bananal do cv. Nanicão em São Miguel do Iguaçu, PR, e precipitações pluviométricas mensais, junho de 2003 a maio de 2004.

Tabela 3. Número de Cosmopolites sordidus, número e porcentagem média das iscas boa, regular e ruim e de insetos por isca, em bananal do cv. Nanicão. São Miguel do Iguaçu, PR, junho de 2003 a maiode 2004.

\begin{tabular}{|c|c|c|c|c|c|c|c|c|c|c|c|c|c|}
\hline & & \multirow[b]{2}{*}{$\mathrm{N}^{\mathrm{o}}$} & \multirow[b]{2}{*}{$\%$} & \multirow[b]{2}{*}{$\mathrm{N}^{\circ}$} & \multicolumn{2}{|c|}{ Isca boa } & \multicolumn{4}{|c|}{ Isca regular } & \multicolumn{3}{|c|}{ Isca ruim } \\
\hline & & & & & $\%$ & $\mathrm{~N}^{\circ}$ & $\%$ & $\mathrm{~N}^{\circ}$ & $\%$ & $\mathrm{~N}^{\circ}$ & $\%$ & $\mathrm{~N}^{\mathrm{o}}$ & $\%$ \\
\hline Meses & $\mathrm{N}^{\circ}$ & iscas & iscas & insetos & insetos & iscas & iscas & insetos & insetos & iscas & iscas & insetos & insetos \\
\hline \multicolumn{14}{|l|}{2003} \\
\hline Junho & 976 & 0 & 0 & 0 & 0 & 100 & 62 & 615 & 63 & 60 & 38 & 361 & 37 \\
\hline Julho & 970 & 0 & 0 & 0 & 0 & 133 & 83 & 834 & 86 & 27 & 17 & 136 & 14 \\
\hline Agosto & 946 & 0 & 0 & 0 & 0 & 117 & 73 & 691 & 73 & 43 & 27 & 255 & 27 \\
\hline Setembro & 832 & 0 & 0 & 0 & 0 & 138 & 86 & 716 & 86 & 22 & 14 & 116 & 14 \\
\hline Outubro & 656 & 42 & 26 & 171 & 26 & 94 & 59 & 387 & 59 & 24 & 15 & 98 & 15 \\
\hline Novembro & 581 & 12 & 7 & 41 & 7 & 73 & 46 & 267 & 46 & 75 & 47 & 273 & 47 \\
\hline $\begin{array}{c}\text { Dezembro } \\
2004\end{array}$ & 515 & 4 & 3 & 10 & 2 & 114 & 71 & 366 & 71 & 42 & 26 & 139 & 27 \\
\hline Janeiro & 489 & 2 & 1 & 5 & 1 & 132 & 83 & 406 & 83 & 26 & 16 & 78 & 16 \\
\hline Fevereiro & 754 & 4 & 3 & 15 & 2 & 133 & 83 & 626 & 83 & 23 & 14 & 113 & 15 \\
\hline Março & 695 & 12 & 8 & 56 & 8 & 141 & 88 & 612 & 88 & 7 & 4 & 28 & 4 \\
\hline Abril & 596 & 0 & 0 & 0 & 0 & 155 & 97 & 578 & 97 & 5 & 3 & 18 & 3 \\
\hline Maio & 464 & 8 & 5 & 23 & 5 & 150 & 94 & 436 & 94 & 2 & 1 & 5 & 1 \\
\hline Total & 88474 & 84 & 4,4 & 321 & 4 & 1480 & 77 & 6534 & 77 & 356 & 18,6 & 1620 & 19 \\
\hline
\end{tabular}




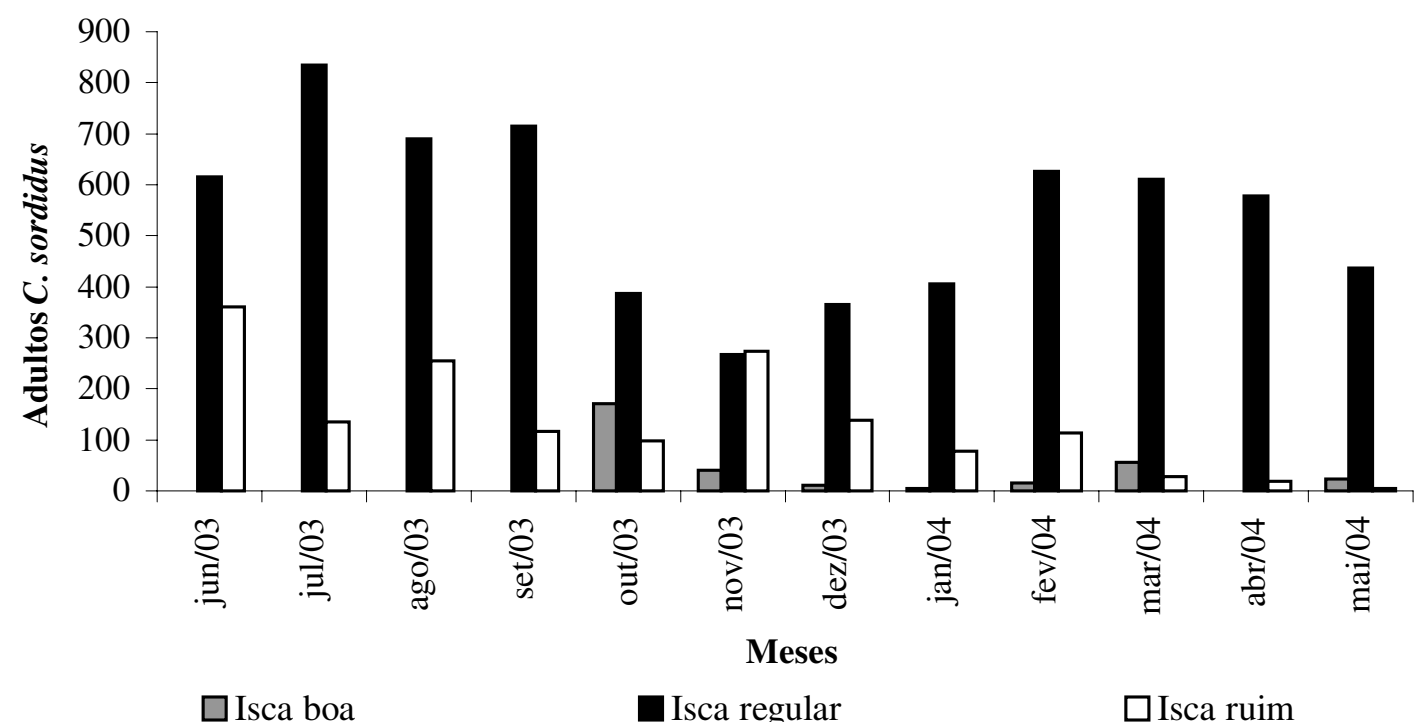

Figura 4. Flutuação populacional de adultos de Cosmopolites sordidus e a atratividade da condição de preservação das iscas, em bananal do cv. Nanicão. São Miguel do Iguaçu, PR, junho de 2003 a maio de 2004.

Tabela 4. Coeficientes de correlação encontrados entre fatores climáticos, estado de conservação da isca e o número mensal de adultos de Cosmopolites sordidus, e interação de adultos de C. sordidus com as iscas boa, regular e ruim, em bananal do cv. Nanicão, em São Miguel do Iguaçu, PR, junho de 2003 a maio de 2004.

\begin{tabular}{ccc}
\hline Fatores climáticos & Equações deregressão & Coeficientes de correlação $(\mathrm{r})$ \\
\hline Isca boa & & $0,45361^{* *}$ \\
Precipitação pluvial $(\mathrm{mm})$ & $\mathrm{y}=0,2329 \mathrm{x}-7,5762$ & $0,27773^{\mathrm{ns}}$ \\
Temperatura máxima $\left({ }^{\circ} \mathrm{C}\right)$ & $\mathrm{y}=3,5235 \mathrm{x}-70,145$ & $0,13779^{\mathrm{ns}}$ \\
Temperatura Mínima $\left({ }^{\circ} \mathrm{C}\right)$ & $\mathrm{y}=1,9988 \mathrm{x}-7,5541$ & $-0,09804^{\mathrm{ns}}$ \\
Umidade relativa do ar $(\%)$ & $\mathrm{y}=-0,5124 \mathrm{x}+58,202$ & \\
Isca regular & & $-0,69597^{*}$ \\
Precipitação pluvial $(\mathrm{mm})$ & $\mathrm{y}=-1,242 \mathrm{x}+727,14$ & $-0,33895^{* *}$ \\
Temperatura máxima $\left({ }^{\circ} \mathrm{C}\right)$ & $\mathrm{y}=-14,946 \mathrm{x}+955,16$ & $-0,52796^{* *}$ \\
Temperatura Mínima $\left({ }^{\circ} \mathrm{C}\right)$ & $\mathrm{y}=-26,62 \mathrm{x}+1000,5$ & $-0,17241^{\mathrm{ns}}$ \\
Umidade relativa do ar $(\%)$ & $\mathrm{y}=-3,1322 \mathrm{x}+737$ & \\
Isca ruim & & $-0,1520^{\mathrm{ns}}$ \\
Precipitação pluvial $(\mathrm{mm})$ & $\mathrm{y}=-0,1754 \mathrm{x}+160,9$ & $-0,14914^{\mathrm{ns}}$ \\
Temperatura máxima $\left({ }^{\circ} \mathrm{C}\right)$ & $\mathrm{y}=-4,2532 \mathrm{x}+251,97$ & $-0,15498^{\mathrm{ns}}$ \\
Temperatura Mínima $\left({ }^{\circ} \mathrm{C}\right)$ & $\mathrm{y}=-5,0535 \mathrm{x}+221,67$ & $0,19465^{\mathrm{ns}}$ \\
Umidade relativa do ar $(\%)$ & $\mathrm{y}=2,287 \mathrm{x}-5,5489$ & \\
Interação adulto e isca & & $-0,21941^{\mathrm{ns}}$ \\
Isca boa & $\mathrm{y}=-0,0568 \mathrm{x}+66,793$ & $0,80926^{*}$ \\
Isca regular & $\mathrm{y}=0,728 \mathrm{x}+30,294$ & $0,5651^{* *}$ \\
Isca ruim & $\mathrm{y}=0.3288 \mathrm{x}-97,087$ & \\
\hline
\end{tabular}

${ }^{*} 0,6 \leq(\mathrm{r}) \leq 1$ variáveis de correlação significativa; ${ }^{* *} 0,3 \leq(\mathrm{r}) \leq 0,6$ correlação relativamente fraca entre as variáveis e ${ }^{\text {ns }} 0<(\mathrm{r})<0,3$ correlação muito fraca entre as variáveis (CRESPO, 1997). 
Constatou-se correlação significativa ( $\mathrm{r}=$ 0,69597) entre a isca regular, a flutuação dos insetos adultos e a precipitação pluviométrica, indicando que nos períodos de maior incidência de chuvas, a isca absorvia muita água, tornando-se um ambiente desfavorável à permanência dos insetos. Tanto é assim que no período de junho a agosto de 2003, a média da precipitação foi de $76 \mathrm{~mm}$ e neste mesmo período, observou-se a maior média de insetos nas iscas (6,0 adulto/isca) e de outubro a dezembro de 2003 a média da precipitação foi a mais alta $(264,6 \mathrm{~mm})$ e a média de insetos nas iscas foi a mais baixa (3,6 adulto/isca) (Tabela 4$)$.

Em relação às larvas, também registrou-se correlação significativa com a isca regular $(r=$
0,97521), indicando que os insetos adultos preferiram as mesmas para ovipositar ou então, as condições não foram favoráveis ao desenvolvimento das larvas nas outras iscas. No entanto, ao contrário dos adultos, verificou-se que as larvas se concentraram na isca regular, no período de maior índice de precipitação 308,6mm, como demonstrado pela correlação positiva entre estas duas variáveis. Provavelmente, isto ocorreu porque a umidade e o material em decomposição da isca são favoráveis à larva, e além disso, dificilmente as larvas se deslocariam da isca, devida sua estrutura morfológica (Tabela 4).

Verificou-se número significativamente superior de adultos de $C$. sordidus (4915) no ambiente sombreado em relação ao ambiente aberto (3559) (Tabela 5).

Tabela 5. Número de Cosmopolites sordidus adulto e porcentagem média de insetos infectados por Beauveria bassiana encontrados nas iscas dispostas nos dois ambientes do bananal do cv. Nanicão. São Miguel do Iguaçu, PR, junho de 2003 a maio de 2004.

\begin{tabular}{|c|c|c|c|c|}
\hline \multirow[b]{2}{*}{ Meses } & \multicolumn{2}{|c|}{ Bananal aberto com invasoras } & \multicolumn{2}{|c|}{ Bananal fechado com sombra } \\
\hline & $\begin{array}{l}\text { Total de adultos } \\
\text { de C. sordidus }\end{array}$ & $\begin{array}{c}\% \text { de C. sordidus } \\
\text { infectados }\end{array}$ & $\begin{array}{l}\text { Total de adultos } \\
\text { de C. sordidus }\end{array}$ & $\begin{array}{c}\% \text { de C. sordidus } \\
\text { infectados }\end{array}$ \\
\hline 2003 & & & & \\
\hline Junho & 312 & 0,0 & 664 & 0,15 \\
\hline Julho & 291 & 0,3 & 679 & 0,59 \\
\hline Agosto & 237 & 0,0 & 709 & 0,28 \\
\hline Setembro & 207 & 0,0 & 625 & 0,96 \\
\hline Outubro & 148 & 2,0 & 508 & 0,98 \\
\hline Novembro & 171 & 0,0 & 410 & 0,24 \\
\hline $\begin{array}{l}\text { Dezembro } \\
2004\end{array}$ & 248 & 0,8 & 267 & 1,50 \\
\hline Janeiro & 347 & 0,6 & 142 & 0,00 \\
\hline Fevereiro & 507 & 0,4 & 247 & 0,00 \\
\hline Março & 451 & 0,4 & 244 & 0,00 \\
\hline Abril & 306 & 0,3 & 290 & 0,34 \\
\hline Maio & 334 & 0,0 & 130 & 0,00 \\
\hline Total & 3559 & 0,4 & 4915 & 0,50 \\
\hline
\end{tabular}




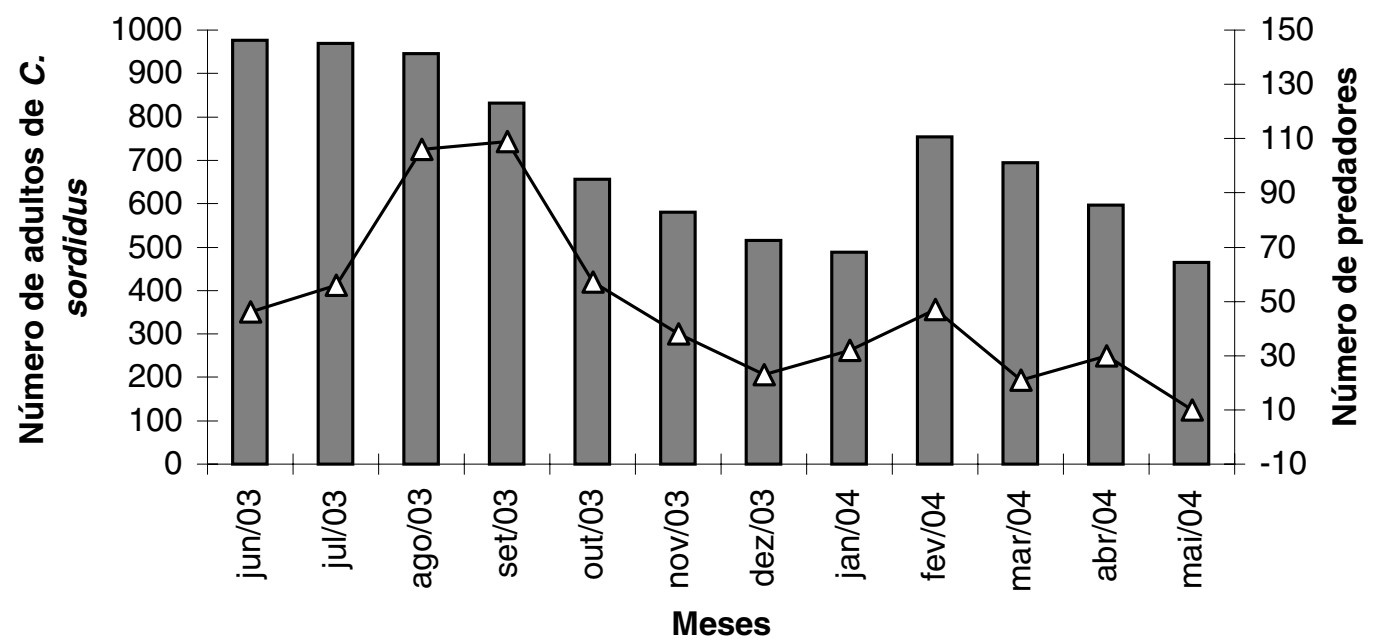

Adultos

$\neg$ Predadores

Figura 5. Interação de adultos de Cosmopolites sordidus e predadores verificados em bananal do cv. Nanicão. São Miguel do Iguaçu, PR, junho de 2003 a maio de 2004.

Esse resultado demonstrou a preferência de $C$. sordidus pelo ambiente do bananal mais fechado, sombreado e úmido, propiciado pelo acúmulo de resíduos da cultura e desprovido de plantas invasoras, quando comparado ao ambiente mais seco, onde as plantas estavam distribuídas desuniformemente, com maior penetração dos raios solares com poucos resíduos e com abundância de plantas invasoras.

A preferência demonstrada pelo inseto neste estudo, provavelmente esteja relacionada às características e hábitos do mesmo, pois se trata de um inseto de hábitos noturnos, sensível a temperaturas elevadas, sendo durante o dia sedentário, buscando abrigo em locais úmidos, de forma a evitar a luz solar, protegendo-se nas bainhas das folhas, resíduos da cultura e touceiras de bananeira (SUPLICY; SAMPAIO, 1982; SILVA, 1985; VIANA, 1992; CARBALLO, 2001; GOLD; PINESE; PEÑA, 2002), cabendo ressaltar, ainda que não se encontraram informações específicas na literatura sobre a heterogeneidade do ambiente do bananal e o estabelecimento de C. sordidus.

Constatou-se a presença de predadores e de insetos infectados por fungo nas iscas, e não se registrou a presença de parasitóide no período do estudo. Dados semelhantes foram relatados por Hasyim e Gold (1998) e Waterhouse (1998), em levantamentos de inimigos naturais do moleque-dabananeira no sudeste da Ásia.

Os predadores amostrados nas armadilhas no decorrer das coletas foram identificados como pertencentes às ordens e famílias: Coleoptera (Carabidae), Dermaptera (Forficulidae), Hemiptera (Reduviidae), Hymenoptera (Formicidae, subfamília Ponerinae) e Aranae (Ctenidae, Clubionidae, Lycosidae), todos registrados por outros autores, como predadores generalistas e oportunistas de $C$. sordidus, geralmente se alimentando de ovos e larvas da praga (KOPPENÖFER et al., 1992; WATERHOUSE, 1998; HASYIM; GOLD, 1998; GOITÍA; CERDA, 1998; TINZAARA; KARAMURAS; TUSHEMEREIRWE, 1999) (Tabela 6).

Registrou-se em maior abundância a ordem Dermaptera, representando $64,2 \%$ do total de predadores encontrados nas armadilhas, seguido pelas aranhas com 19,1\% e Hymenoptera com 11,1\%, sendo identificada apenas o gênero Pachycondyla sp. (Tabela 6). 
Tabela 6. Número de predadores e respectivas porcentagem, registrado mensalmente nas iscas, em bananal do cv. Nanicão. São Miguel do Iguaçu, PR, junho de 2003 a maio de 2004.

\begin{tabular}{|c|c|c|c|c|c|c|}
\hline \multicolumn{7}{|c|}{$\%$ de Predadores iscas /mês } \\
\hline Meses & $\mathrm{N}^{\mathrm{o}}$ de predadores & Dermaptera & Aranae & Hymenoptera & Coleoptera & Hemiptera \\
\hline \multicolumn{7}{|l|}{2003} \\
\hline junho & 46 & 78,3 & 8,7 & 8,7 & 4,3 & - \\
\hline julho & 56 & 69,6 & 12,5 & 12,5 & 3,6 & 1,8 \\
\hline agosto & 106 & 73,6 & 14,2 & 5,7 & 4,7 & 1,8 \\
\hline etembro & 109 & 73,4 & 14,7 & 7,3 & 4,6 & - \\
\hline outubro & 57 & 42,1 & 36,8 & 15,8 & 1,8 & 3,5 \\
\hline ovembro & 38 & 31,6 & 47,4 & 15,8 & 5,2 & - \\
\hline ezembro & 23 & 34,9 & 39,1 & 13,0 & 13,0 & - \\
\hline 2004 & & & & & & \\
\hline janeiro & 32 & 59,4 & 9,4 & 25,0 & 6,2 & - \\
\hline evereiro & 47 & 70,2 & 17,0 & 6,4 & 4,3 & 2,1 \\
\hline março & 21 & 61,9 & 19,1 & 14,3 & 4,7 & - \\
\hline abril & 30 & 73,4 & 10,0 & 13,3 & 3,3 & - \\
\hline maio & 10 & 50,0 & 20,0 & 30,0 & - & - \\
\hline Total & 575 & 64,2 & 19,1 & 11,1 & 4,6 & 1,0 \\
\hline
\end{tabular}

Nas avaliações realizadas, observou-se que esses organismos interferiram na flutuação da população de adultos da praga, pois a análise de correlação entre os mesmos foi significativa $(r=0,674565)$ (Tabela 7).

A elevação gradativa da população de predadores foi acompanhada pelo aumento da população da praga, pois quando os picos dos adultos ocorreram em junho e julho, nos dois meses seguintes, ocorreram os picos populacionais dos predadores, o que culminou na redução da praga, e na seqüência também decresceu o número de predadores (Figura 5).

Resultados semelhantes foram obtidos por Martínez e Godoy (1991), em estudo da dinâmica populacional do predador Hololepta quadridentata Fabricius (Coleoptera, Histeridae) e da população de $C$. sordidus, em bananal na Venezuela. Os autores observaram que à medida que a população de praga cresceu, no mês seguinte, também aumentou a população desse predador, posteriormente provocando uma diminuição em ambas as populações nos meses sucessivos.

Os adultos de $C$. sordidus, além de serem fortemente protegidos pelo exoesqueleto, vivem entre os resíduos da planta que dificultam a sua predação. No entanto, as formas de ovo, larva e pupa são as mais vulneráveis ao ataque de predadores (KOPPENÖFER et al., 1992; WATERHOUSE, 1998; GOITÍA; CERDA, 1998). Relacionado a essa questão, verificou-se que o número de larvas de $C$. sordidus encontrados foi bem menor que o número de adultos, sendo possível argumentar, através da análise gráfica, que sempre que ocorreram os picos de predadores, o número de larvas caiu significativamente; além disso, o baixo número de larvas, provavelmente ocorreu devido ao fato das mesmas serem mais visadas pelos predadores (Figura 6).

A ação dos predadores sobre as fases imaturas do desenvolvimento de C. sordidus foi amplamente revisada por Waterhouse (1998), que citou Euborellia e Labia como importantes predadores de ovos e larvas, Reduviidae predadores de larvas, Carabidae predadores de ovos e larvas, Diptera e Formicidae como predadores de ovos e larvas. Na Uganda, Tinzaara, Karamuras e Tushemereirwe (1999), em estudo da avaliação do potencial de predadores de C. sordidus, coletados 
em pseudocaules de banana em decomposição, identificaram Euborellia e Labia e Ponerinae como os predadores mais comuns e ativos.

Assim como no Kenya, Koppenhöfer et al. (1992) realizaram um estudo detalhado sobre os inimigos naturais de $C$. sordidus e identificaram 12 predadores, todos polífagos, atacando ovos, larva e pupas, mas nenhum se alimentou de adultos da praga.

Entre os predadores, Dactylosternum abdominale (Coleoptera, Hidrophilidae), nos testes de laboratório reduziu a população de larvas do moleque nos pseudocaules da bananeira, entre 40 a 90\% sob diferentes densidades do predador.

Observou-se no presente estudo a ocorrência geralmente solitária, da formiga Pachyconyla sp. No Brasil, essa família é considerada importante predadora, principalmente a espécie $P$. obscuriocornis Emergy, que se apresentou como uma predadora voraz de ninfas da cigarrinha-daspastagens (Deois flavopicta Stal), podendo a mesma se deslocar a distâncias superiores a 10 m, em busca de presas, tendo hábito solitário de caça e aumentando sua taxa de predação com a abundância da praga (SUJII et al., 2004).

Também, Goitía e Cerda (1998), na Venezuela, verificaram que as formigas foram as mais abundantes, destacando-se Azteca foreli Emergy $(73,2 \%)$ e outras da subfamília Ponerinae como importantes predadoras de ovos, já que as mesmas estabelecem seus ninhos na base das plantas, sítios de ovoposição de C. sordidus.

$\mathrm{Na}$ interação dos fatores climáticos com os predadores, observou-se pouca influência dos mesmos sobre a dinâmica dos predadores, sendo o fator determinante para os predadores, a população da presa, que apresentaram uma correlação significativa ( $\mathrm{r}=0,674565)$ com os adultos de $C$. sordidus, porém, como a maioria são generalistas, não é viável considerar apenas esta espécie como capaz de interferir na sua dinâmica.

De um total de 8474 adultos de $C$. sordidus contabilizados nas iscas, $0,44 \%$ estavam mortos pelo fungo $B$. bassiana. Resultado semelhante de baixa infestação foi registrado por Silva (1985), na Paraíba, em cultivo de bananeira do cv. prata, com $0,97 \%$ de adultos parasitados por B. bassiana.

Confrontando-se o pico populacional de adultos de $C$. sordidus e a incidência de fungos na população do inseto, verificou-se que não houve correlação significativa $(r=0,131042)$ entre eles, haja visto que o pico populacional do inseto ocorreu nos meses de junho e julho, com média de 6,1 insetos/isca, e o maior número de insetos infectados ocorreram em setembro e outubro, diminuindo no restante do período.

Da mesma forma, Batista Filho et al. (1992), em Miracatu, estado de São Paulo, em bananal cultivado com o cv. prata, registraram pico populacional de $C$. sordidus, em abril e o índice de adultos infectados por B. amorpha em janeiro. Contudo, os autores verificaram índices de parasitismo mais altos, com infecção média natural de $9,3 \%$ por $B$. amorpha e o pico ocorreu em janeiro com 17,0\%, em área com cultivo do cv. prata.

Os índices de infestação natural causada pelo fungo, foram baixos, provavelmente devido ao número insuficiente de propágulos viáveis do fungo capazes de iniciar infecção no hospedeiro, pois segundo Alves e Leucona (1998) é necessário um potencial de inóculo mínimo, em uma dada área, para a ocorrência de uma doença e conseqüentemente epizootias.

Outro fator a se considerar corresponde à falta de interações entre os três fatores principais, quais sejam: o fungo, a praga e os fatores ambientais favoráveis, pois nos períodos de picos da praga, as precipitações pluviométricas foram baixas, acarretando em menor umidade relativa do ar condições não favoráveis à germinação e penetração dos esporos do fungo no hospedeiro e, quando as precipitações foram mais elevadas, o número de hospedeiros foi o mais baixo.

Segundo Alves e Leucona (1998), a umidade relativa do ar é essencial para os fungos entomopatogênicos, principalmente para as fases de 


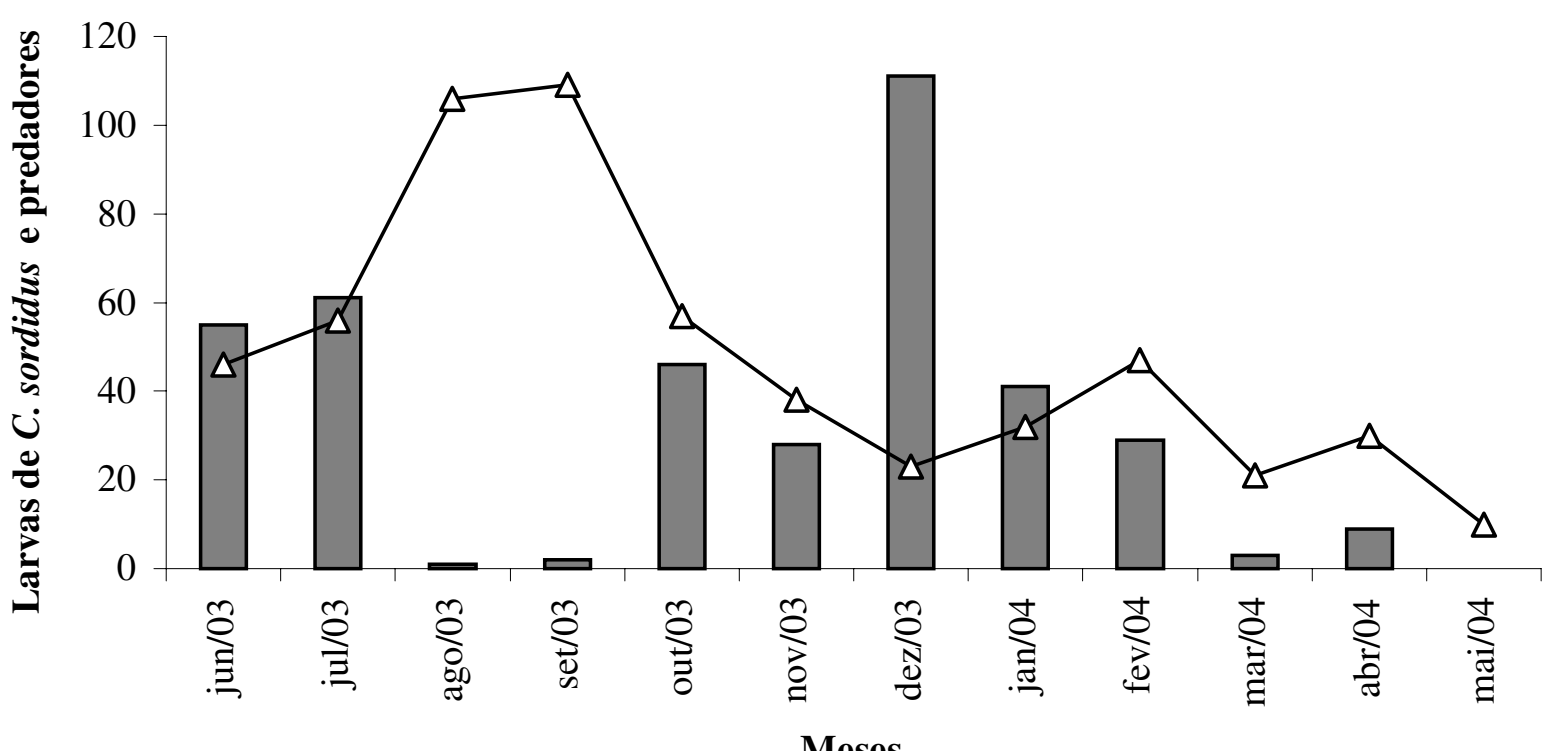

$\square$ Larvas de C. sordidus

$\triangle-$ Predadores

Figura 6. Interação de larvas de Cosmopolites sordidus e predadores verificados em bananal do cv. Nanicão. São Miguel do Iguaçu, PR, junho de 2003 a maio de 2004.

Tabela 7. Equações de regressão e coeficientes de correlação encontrados entre: o número mensal de predadores e adultos infectados por Bauveria basssiana por isca, e os dados climáticos; interações entre adultos e larvas de Cosmopolites sordidus com predadores e fungos por isca em bananal do cv.Nanicão.São Miguel do Iguaçu, PR, junho de 2003 a maio de 2004.

\begin{tabular}{lcc}
\hline \multicolumn{1}{c}{ Fatores ambientais } & Equações de regressão & Coeficientes de correlação $(\mathrm{r})$ \\
\hline Predadores & $\mathrm{y}=-0,1153 \mathrm{x}+64,888$ & $-0,35122^{* *}$ \\
Precipitação pluvial $(\mathrm{mm})$ & $\mathrm{y}=-1,8731 \mathrm{x}+99,397$ & $-0,23082^{\mathrm{ns}}$ \\
Temperatura máxima $\left({ }^{\circ} \mathrm{C}\right)$ & $\mathrm{y}=-4,42 \mathrm{x}+123,65$ & $-0,47635^{* *}$ \\
Temperatura Mínima $\left({ }^{\circ} \mathrm{C}\right)$ & $\mathrm{y}=-0,68 \mathrm{x}+89,73$ & $-0,20339^{\mathrm{ns}}$ \\
Umidade relativa do ar $(\%)$ & & $0,335318^{* *}$ \\
& & $0,240358^{\mathrm{ns}}$ \\
Adultos infectados $(\%)$ & $\mathrm{y}=0,0084 \mathrm{x}+1,8416$ & $0,076478^{\mathrm{ns}}$ \\
Precipitação pluvial $(\mathrm{mm})$ & $\mathrm{y}=0,1495 \mathrm{x}-1,0248$ & $-0,09526^{\mathrm{ns}}$ \\
Temperatura máxima $\left({ }^{\circ} \mathrm{C}\right)$ & $\mathrm{y}=0,0544 \mathrm{x}+2,1516$ & \\
Temperatura Mínima $\left({ }^{\circ} \mathrm{C}\right)$ & $\mathrm{y}=-0,0244 \mathrm{x}+4,5841$ & $0,674565^{*}$ \\
Umidade relativa do ar $(\%)$ & & $-0,26091^{\mathrm{ns}}$ \\
Interação & $\mathrm{y}=4,0745 \mathrm{x}+510,93$ & $0,131042^{\mathrm{ns}}$ \\
Adultos C. sordidus/predadores & $\mathrm{y}=-0,2781 \mathrm{x}+45,49$ & $\mathrm{y}=10,328 \mathrm{x}+674,32$ \\
Larvas C. sordidus/predadores & & \\
Adultos C. sordidus/ B. bassiana & & \\
\hline
\end{tabular}


disseminação, germinação e penetração no hospedeiro, sendo que no presente estudo a umidade relativa do ar não foi significativa na infestação do fungo (Tabela 7).

Os autores, ainda salientam que a umidade presente sobre os insetos, ou sobre o habitat dos mesmos, é a mais importante para a ocorrência de doenças quando comparada com a umidade relativa do ar. Em umidades mais baixas, o fungo B. bassiana consegue infectar insetos, mas às vezes não esporula sobre o cadáver, levando à uma subestimativa da ocorrência do fungo no ambiente. Além da umidade, outro fator importante para um bom desenvolvimento do fungo é a temperatura, que para $B$. bassiana, a faixa ideal se encontra entre 22 a $26^{\circ} \mathrm{C}$.

Avaliação da Patogenicidade de Isolados de B. Bassiana para Adultos de C. Sordidus

Embora todos os isolados tenham apresentado atividade patogênica, não houve diferença entre eles e a mortalidade confirmada foi considerada baixa, quando comparada aos resultados obtidos por Jordão et al. (1999), que em laboratório obtiveram para o isolado CB 66 o melhor desempenho, dentre os isolados testados, infectando entre $45 \%$ da população de adultos de $C$. sordidus (Tabela 8).

Tabela 8. Mortalidade média de Cosmopolites sordidus, observada em 20 dias após a suspensão em conídios de Beauveria. bassiana (Temperatura $25 \pm 1{ }^{\circ} \mathrm{C}$, Umidade Relativa $70 \pm 10 \%$ e Fotofase de 12 horas).

\begin{tabular}{cc}
\hline Isolados & Mortalidade $(\%)^{1}$ \\
\hline UNIOESTE 39 & $25 \mathrm{a}$ \\
CB 66 $620 \mathrm{a}$ \\
UEL 50 & $17 \mathrm{a}$ \\
UEL 25 & $15 \mathrm{a}$ \\
\hline
\end{tabular}

${ }^{1}$ Médias originais seguidas de mesma letra não diferem entre si ao nível de $5 \%$ de probabilidade, pelo teste de Tukey; C.V. $=44,8 \%$

Provavelmente, a baixa mortalidade de $C$. sordidus causada pela ação dos isolados de $B$. bassiana avaliados neste estudo, foi devida à ação de microrganismos saprofíticos presentes nos pseudocaules de bananeira utilizados para alimentar os insetos, durante o período de avaliação. Pois, segundo Alves e Lecuona (1998) o poder microbiano antagônico, exercido por Trichoderma, actinomicetos e outros microrganismos saprofíticos é altamente prejudicial ao desenvolvimento de fungos entomopatogênicos.

Outra questão que pode ter influenciado nos resultados obtidos corresponde à baixa susceptibilidade da população de insetos aos isolados de B. bassiana avaliados.

\section{Referências}

ALVES, S. B.; LECUONA, R. E. Epizootiologia aplicada ao controle microbiano de insetos. In: ALVES, S. B. Controle microbiano de insetos. Piracicaba: FEALQ, 1998. Cap.5, p.97-169.

ARLEU, J. R. Dinâmica populacional e controle do Cosmopolites sordidus (Germ., 1824) e Metamasius hemipterus L., 1764 (Col.: Curculionidae), em bananas da cv. Prata, no Espírito Santo. 1982. Dissertação (Mestrado em Ciências Biológicas na área de Entomologia) - Escola Superior de Agricultura Luiz de Queiroz, Piracicaba.

ARLEU, J. R.; SILVEIRA NETO, S.; GOMES, J. A.; NÓBREGA, C. A. Movimentação mensal da broca-dabananeira, em bananais da cv. Prata, na região produtora do Espírito Santo. Campo Grande: Ed. Empresa Capixaba de Pesquisa Agropecuária (ENCAPA), 1985. p.1-5.

BATISTA FILHO, A.; LEITE, L. G; SATO, M. E.; RAGA, A. Cosmopolites sordidus (Germar, 1824) em dois cultivares de banana: nível de infestação e incidência natural do entomopatógeno Beauveria amorpha (Höhn). Revista de Agricultura, Piracicaba, v.67, p.183-190, 1992.

BATISTA FILHO, A.; SATO, M. E; RAGA, A.; LEITE, L. G.; PRADA, A. Flutuação populacional da broca da bananeira (Cosmopolites sordidus, Germar) em Miracatu, SP. Ecossistemas, São Paulo, v.16, p.46-53, 1991.

BATISTA FILHO, A.; TAKADA, H. M.; CARVALHO, A. G. Brocas da bananeira. In: REUNIÃO ITINERANTE DE FITOSSANIDADE DO INSTITUTO BIOLÓGICO BANANA, 6., 2002, São Bento do Sapucaí - SP, 2002. Anais... São Paulo: Instituto Biológico, 2002. p.1-16.

CARBALLO, M. Opcciones para el manejo del picudo negro del plátano. Manejo Integrado de Plagas y agroecologia, Turialba, n.59, p.22-30, 2001. 
CRESPO, A. A. Estatística fácil. 14. ed. São Paulo: Saraiva, 1997.

FANCELLI, M. Pragas. In: ALVES, E. J. Cultura da banana : aspectos técnicos, socioeconômicos e agroindustriais. Brasília,DF: Embrapa, 1999. cap.14, p.409-480.

FAZOLIN, M.; LEDO, A. S; AZEVEDO, F. F. Manejo preventivo da broca do rizoma da bananeira no Acre. Acre: EMBRAPA, 2000. (Comunicado Técnico, n.110). p.1-3.

GALLO, D.; NAKANO, O.; SILVEIRA NETO, S.; CARVALHO, R. P. L.; BATISTA, G.C; BERTI FILHO, E.; PARRA, J. R. P.; ZUCCHI, R. A.; ALVES, S. B.; VENDRAMIN, J. D.; MARCHINI, L. C.; LOPES, J. R. S.; OMOTO, C. Entomologia agrícola. São Paulo: Agronômica Ceres, 2002. v.10.

GOITÍA, W.; CERDA, H. Hormigas y otros insectos asociados a musáceas (Musa spp.) su relación con Cosmopolites sordidus Germar (Coleoptera, Curculionidae). Agronomia Tropical, Maracay, v.48, n.2, p.209-224,1998.

GOLD, C. S.; PINESE, B.; PEÑA, J E. Pests of Banana. In: PEÑA, J. E. (Ed.) Tropical fruit pests and pollinators: biology, economic importance, natural enemies and control. Florida: Cabi Publishing, 2002. cap.2, p.13-32.

GOLD, C. S.; RUKAZAMBUGA, N. D. T. M.; KARAMURA, E. B.; NEMEYE, P.; NIGHT, G. Recent advances in banana weevil biology, population dynamics and pest status with emphasis on East Africa. In: WORKSHOP ON BANANA IPM HELD, 1998, Nelspruit. Proceedings... Nelspruit: INIBAP, 1998. p.35-50.

HASYIM, A.; GOLD, C. S. Potential of classical biological control for banana weevil, Cosmopolites sordidus Germar, with natural enemies from Asia (with enphasis on Indonesia). In: WORKSHOP ON BANANA IPM HELD, 1998, Nelspruit. Proceedings... Nelspruit: INIBAP, 1998. p.59-71.

JORDAO, A. L.; BATISTA FILHO, A.; LEITE, L.G.; BERIAM, L.; ALMEIDA, J.E.M. Caracterização e eficiencia de isolados de Beauveria bassiana (Bals.) Vuill no controle de Cosmopolites sordidus. Arquivos do Instituto Biológico, São Paulo, v.66, n.2, p.107-111, 1999.

KOPPENÖFER, A. M.; SESHU REDDY, K. V.; MADEL, G.; LUBEGA, M. C. Predators of the banana weevil, Cosmopolites sordidus (Germar) (Col., Curculionidae) in Western Kenya. Journal Applied Entomology, Berlin, v.114, p.530-533, 1992.

MARTÍNEZ, N. B.; GODOY, F. G. Épocas de incidência de Cosmopolites sordidus G.y de Metamasius hemipterus L. en dos huertos de musaceasen el Estado Aragua. Agronomía Tropical, Caracas, v.38, n.4/6, p.107-119, 1988.
MARTÍNEZ, N. B.; GODOY, F. G. Hololepta (Lioderma) quadridentata Fabricius depredador del gorgojo negro del platano. Agronomía Tropical, Caracas, v.41, n.5, p.285290, 1991.

MCINTYRE, B. D.; GOLD, C. S.; SSALI, H.; RIHA, S. J. Effects of mulch location on banana weevil, soil and plant nutrients, soil water and biomass in banana fields. Biology and fertility of soils, Berlin, v.39, p.74-79, 2003.

OLIVEIRA, C. A P.; SOUZA, C. M. Influência da cobertura morta na umidade, incidência de plantas daninhas e de broca-do-rizoma (Cosmopolites sordidus) em um pomar de bananeiras (Musa spp.). Revista Brasileira de Fruticultura, Jaboticabal, v.25, n. 2, p.345-347, 2003.

PRANDO, H. F.; LICHTEMBERG, L. A.; HINZ, R. H. Flutuação populacional da broca da bananeira (Cosmopolites sordidus) (Col., Curculionidae). In: CONGRESSO BRASILEIRO DE ENTOMOLOGIA RESUMOS DO INSTITUTO AGRONÔMICO. 40., 1987, Campinas. Resumos... Campinas: Instituto Agronômico de Campinas, 1987. p.137.

SILVA, C. G. Estudo do comportamento da broca da bananeira Cosmopolites sordidus (GERMAR, 1824) (Col.: Curculionidae), visando ao seu controle. 1985. Tese (Doutorado em Ciências Biológicas na Área de Entomologia). - Escola Superior de Agricultura Luiz de Queiroz, Piracicaba.

SUJII, E. R.; GARCIA, M. A.; FONTES, E. M. G.; O'NEILL, R. J. Pachycondyla obscuricornis as natural enemy of the spittlebug Deois flavopicta. Pesquisa Agropecuária Brasileira, Brasília, v.39, n.6, p.607-609, 2004.

SUPLICY FILHO, N.; SAMPAIO, A. S. Pragas da bananeira. Biológico, São Paulo, v.48, n.7, p.169-182, 1982.

TINZAARA, W.; KARAMURA, E.; TUSHEMEREIRWE, W. Observaciones preliminares sobre los inemigos naturales asociados con el picudo negro del banano Cosmopolites sordidus Germar en Uganda. Infomusa : The International Magazine on banana and Plantain, Paris, v.8, n.1, p.28-30, 1999.

VIANA, A. M. M. Comportamento de agregação e acasalamento de Cosmopolites sordidus (Coleoptera: Curculionidae) mediado por semioquímicos, em olfatômetro. Minas Gerais. 1992. Tese ("Magister Scientiae" de Entomologia) - Universidade Federal de Viçosa, Viçosa.

WATERHOUSE, D. F. Biological control of insect pests: Southeast Asian prospects. 1998. Dissertação - (Mestrado) Australian Centre For International Agricultural Research, Canberra, Australia. 